\title{
Educação em saúde na rede municipal de saúde: práticas de nutricionistas
}

\author{
Health education and the municipal health network: \\ practices of nutritionists
}

Mariana de Sousa Nunes Vieira (https://orcid.org/0000-0002-4832-6494) ${ }^{1}$

Karolina Kellen Matias (https://orcid.org/0000-0002-4527-1467) ${ }^{2}$

Maria Goretti Queiroz (https://orcid.org/0000-0002-7363-4835) ${ }^{3}$

${ }^{1}$ Programa de PósGraduação em Ciências da Saúde, Universidade Federal de Goiás (UFG). Praça Universitária s $/ \mathrm{n}^{\circ}$, St. Universitário. 74605-220

Goiânia GO Brasil.

marisnunes.nut@gmail.com.

${ }^{2}$ Pontifícia Universidade

Católica de Goiás. Goiânia

GO Brasil.

${ }^{3}$ Faculdade de Odontologia,

UFG. Goiânia GO Brasil.
Abstract Health education must be seen as an instrument used to promote quality of life. The objective of this study was to evaluate health education practices of nutritionists in a municipal health network. This is a qualitative study using Grounded Theory. Interviews and observation of educational activities were carried out. The use of materials was evaluated, together with attempts to engage the service users. Five analysis categories were applied. The intention of raising awareness and changing habits highlights the preference of professionals toward actions that are articulated and consistent with reality. Productivity valorization, insufficient training, and lack of physical structure were mentioned as restrictions. Most respondents did not evaluate results; they believe in sharing knowledge as a process that transforms reality; and defend the multidisciplinary approach and care by putting the concepts of integrality and equity into practice. The nutritionists' concepts of health education guide their professional performance, as they reflect the perspectives of the educational practices adopted.

Key words Health education, Food and nutrition education, Nutritionists
Resumo A educação em saúde deve ser vista como instrumento de promoção da qualidade de vida. O objetivo do presente trabalho foi avaliar práticas de educação em saúde de nutricionistas de rede municipal de saúde, em uma cidade da região centro-oeste. Optou-se pela pesquisa qualitativa e, especificamente, pela teoria fundamentada nos dados. Foram realizadas entrevistas e observação de atividades educativas $e$, por meio dessas, avaliou-se a utilização de recursos materiais, estratégias e, ainda, a tentativa de envolver os usuários do serviço. Foram definidas cinco categorias de análise. A intenção da conscientização e a mudança de hábitos salienta a predileção do profissional por ações articuladas e coerentes com a realidade. Valorização da produtividade, insuficiência de capacitação, a falta de estrutura física foi citada como limitação. A maioria das entrevistadas não avalia resultados; acredita no compartilhamento de saberes como processo transformador da realidade e defende o trabalho multiprofissional e o cuidado em colocar em prática a integralidade e a equidade. As concepções de educação em saúde dos nutricionistas implicam em sua atuação profissional pois refletem a perspectiva das práticas educativas desenvolvidas.

Palavras-chave Educação em saúde; Educação alimentar e nutricional, Nutricionista 


\section{Introdução}

Nas atividades de educação em saúde, tradicionalmente, se utiliza estratégias de ensino calcadas na transmissão de conhecimento, sem, no entanto, considerar as particularidades do indivíduo. Tal método cunhado como educação bancária ${ }^{1}$, consiste no depósito de informações e exige que o educando absorva os conhecimentos transferidos pelo educador.

Neste modo de agir, o profissional transmite informações, regras e prescrições a fim de evitar ou tratar doenças sem considerar as condições individuais de cada indivíduo. Esse modus operandi acaba isentando o profissional da responsabilidade com a saúde do indivíduo, uma vez que o objetivo dessa interação não prevê o compartilhamento das experiências e troca de informações entre as partes ${ }^{1}$.

Em consequência disso, a educação em saúde começou a ser repensada a partir de mudanças de hábitos de vida, que difundiram a saúde como fator resultante dos determinantes que envolvem as pessoas: as condições biológicas, mentais, sociais e culturais a que estão expostos. Nessa perspectiva, as práticas de educação em saúde voltaram o olhar para as ações preventivas e não prioritariamente as de cunho curativo ${ }^{2}$.

Ao assumir essa nova postura, a educação em saúde se torna um instrumento importante capaz de promover mudanças de comportamento da população. Desta forma, a educação em saúde fomenta, no indivíduo e no grupo, a capacidade de analisar a sua realidade, como também de decidir ações conjuntas com os profissionais de saúde, tecendo uma relação dialética².

Quanto às práticas de educação pelo nutricionista, vale ressaltar a alimentação saudável como uma das ações de promoção de saúde em sua atuação na Atenção Básica em Saúde (ABS). Ressaltando também este nível de atenção à saúde como uma estratégia para integrar ações curativas e preventivas. Este modelo de reorientação da assistência, contraria a concepção biologicista que prevaleceu no Brasil antes da criação do Sistema Único de Saúde (SUS) ${ }^{3}$.

A Estratégia Saúde da Família (ESF) é responsável pela execução das ações de $\mathrm{ABS}$, com foco nos problemas de saúde de maior prevalência e nos grupos mais vulneráveis ao adoecimento. A proposta da ESF deve atuar a favor da equidade para amenizar os riscos que circundam determinada comunidade ${ }^{3,4}$.

A principal meta é a prevenção de doenças e agravos, por meio do estímulo à adesão de há- bitos mais saudáveis. Um dos objetivos da ESF é a produção social de saúde, pautada na troca de informações e experiências entre os profissionais e as famílias assistidas, tendo como recurso a educação em saúde ${ }^{4}$.

Na Atenção Básica, o nutricionista pode se integrar ao Núcleo de Apoio à Saúde da Família (NASF), recentemente denominado Núcleo Ampliado de Saúde da Família e Atenção Básica (NASF-AB), com a publicação da nova Política Nacional de Atenção Básica (PNAB) 4 . A proposta do NASF é garantir efetividade e resolutividade na atenção à saúde, além de ampliar o escopo das ações com a inserção de equipes multiprofissionais para contemplar a integralidade do cuidado ${ }^{5}$.

As ações do NASF abrangem duas dimensões: técnico-pedagógica, na qual a equipe oferece suporte à gestão e auxilia na construção do projeto terapêutico singular e educação continuada das equipes; e clínico-assistencial, que abarca os atendimentos individuais, as visitas domiciliares e as práticas educativas em saúde em grupos ${ }^{5}$.

A partir do conceito de clinica ampliada, contemplada nas ações clinico-assistenciais, o nutricionista compreende, numa concepção integral, o processo saúde-doença dos indivíduos e das coletividades. Ao exercer o acolhimento e a escuta, o profissional identifica as reais condições de vida prevalentes no território adscrito ${ }^{6}$.

Dentre os elementos da educação em saúde, pode-se destacar a prática da Educação Alimentar e Nutricional (EAN), processo no qual o nutricionista é o mediador, ao desenvolver as atividades educativas que busca a troca e a construção de conhecimentos, tornando o usuário um sujeito ativo no processo. Modo de proceder que contribui, de forma mais efetiva, para as mudanças de comportamento alimentar dos indivíduos?

$\mathrm{Na}$ visão do Ministério da Saúde $(\mathrm{MS})^{8}$ a EAN se constitui como uma área de produção de conhecimento tanto no contexto do Direito Humano, da Alimentação Adequada, quanto na garantia da Segurança Alimentar e Nutricional em todas as dimensões e níveis de gestão pública.

É uma tentativa multiprofissional para estimular a autonomia na escolha dos hábitos alimentares saudáveis, desde que, na sua aplicação, o nutricionista utilize recursos orientados por metodologias ativas, como a problematização, que possibilita a interação da comunidade e aborda as nuances do comportamento alimentar em seus aspectos gerais; ou seja, social, biológico e psicológico.

Diante desta lógica, cabe ao nutricionista, que atua como educador, investigar os hábitos 
da população com a qual irá trabalhar a fim de conhecer suas peculiaridades. O nutricionista precisa compreender como o indivíduo elabora a ideia do comportamento alimentar e incentivá-lo a confrontar com as representações sociais e emocionais dos alimentos com as quais lida. A partir disso, construir novos sentidos coerentes, concomitantemente, com a saúde, o prazer, o bem-estar, as questões sanitárias e ambientais ${ }^{9}$.

Partindo dessas reflexões, concebeu-se este estudo com o objetivo de avaliar as práticas de educação em saúde por nutricionistas de um serviço de saúde.

\section{Métodos}

Trata-se de uma pesquisa qualitativa, uma vez que se pretende aprofundar o olhar a respeito dos valores, práticas, linhas de ação e hábitos de grupos sobre a saúde ${ }^{10}$. Esse tipo de pesquisa se aplica ao estudo de percepções e opiniões, à investigação de grupos de pessoas e suas histórias sob a ótica dos próprios indivíduos, suas relações com o mundo. Essa abordagem possibilita explorar eventos sociais pouco conhecidos referentes a grupos restritos e contribui para a construção de novas ideias e conceitos durante a pesquisa, sendo assim utilizada para elaboração de novas hipóteses e novos indicadores qualitativos ${ }^{10}$.

No âmbito da investigação qualitativa podemos encontrar uma diversidade de estratégias metodológicas, dentre elas optou-se pela teoria derivada de maneira indutiva dos dados. Nessa estratégia, os dados são sistematicamente combinados e analisados ao longo de todo o processo da pesquisa, denominada Grounded Theor $y^{11,12}$.

Foram incluídos no estudo os nutricionistas que desenvolvem atividades de educação em saúde, lotados nas unidades da Secretaria Municipal de Saúde (SMS) de um município da região Centro-Oeste do Brasil, abrangendo os Distritos Sanitários (DS), os NASF e as unidades de saúde, que são espaços de atividades educativas. Para a Teoria Fundamentada nos Dados (TFD) a população junto a qual o estudo foi realizado denomina-se amostragem teórica ${ }^{11,12}$.

Foram identificados 34 nutricionistas lotados na Secretaria Municipal de Saúde do município em estudo, todos foram convidados via e-mail a participar da pesquisa. $\mathrm{Na}$ amostragem teórica foram incluídos nove nutricionistas, que aceitaram o convite, todas do sexo feminino e que tinham vínculo efetivo com o município por meio de concurso público.
A saturação teórica dos dados é atingida quando as informações começam a se repetir e não se encontra mais novos dados. Nesta pesquisa, a saturação teórica foi atingida na nona entrevista. Os dados coletados foram suficientes para a realização do estudo, e responderam aos objetivos propostos pelo mesmo ${ }^{13}$.

A coleta de dados foi realizada pela própria pesquisadora, no período de fevereiro a abril de 2014, no local de trabalho de cada nutricionista, que assinaram o Termo de Consentimento Livre Esclarecido (TCLE). A entrevista foi gravada em celular e posteriormente transcrita para o software de avaliação (WebQDA), cada uma com tempo de aproximadamente 15 minutos.

Utilizou-se a técnica de observação simples da rotina desses profissionais com a finalidade de conhecer como as atividades educativas eram realizadas pelas profissionais: recursos utilizados, interação com os participantes, acompanhamento e avaliação dos resultados.

A observação é uma técnica com papel fundamental na pesquisa qualitativa, traz a vantagem da percepção direta dos fatos, sem intermediação ${ }^{10}$. No presente estudo, utilizou-se a observação simples, em que o pesquisador é um expectador, a observação é espontânea e informal, porém vai além da constatação dos fatos. Foi utilizado um diário de campo como instrumento de registro dos elementos observados para posterior sistematização dos dados. Este diário serviu também para a pesquisadora fazer anotação dos chamados "lembretes", ou seja, ideias e observações que foram surgindo e que auxiliaram no desenvolvimento da teoria ${ }^{14}$.

A partir dos relatos das profissionais, foi realizada a transcrição dos mesmos e analisados cada parágrafo, linha por linha a fim de buscar os fatos. Essa fase é denominada de codificação. Desses relatos e observações foram extraídos os trechos e marcados os principais pontos com códigos. Estes foram agrupados em conceitos semelhantes. Dos conceitos aglutinados, foram formadas as subcategorias e as categorias que são as bases para a criação da teoria.

O processo descrito acima é denominado de modelo conceitual, que abrange toda a discussão proveniente das informações encontradas ao longo da pesquisa de campo. Após a coleta de dados, a transcrição, a codificação e a categorização, o pesquisador extrai ideias e conceitos coerentes, a partir do material analisado e, à luz da literatura, redige a teoria. Diante disso, compreende-se que esse método envolve a geração de teoria fundamentada nos dados ${ }^{11}$. Essas categorias serão evidenciadas no decorrer do texto. 
Este estudo foi conduzido de acordo com as normas vigentes estabelecidas pela resolução $466 / 12^{15}$ para o desenvolvimento de pesquisas em saúde no Brasil e submetido para aprovação do Comitê de Ética em Pesquisa da Universidade Federal de Goiás (UFG).

\section{Resultados e discussão}

Das nove profissionais entrevistadas, apenas cinco tinham atividade educativa programada até a data da coleta. Portanto, foi realizada a observação de cinco atividades de educação em saúde.

Os relatos geraram categorias induzidas e emergentes, que possibilitaram uma discussão a respeito da atuação dos nutricionistas e como é a realidade da prática profissional. Alguns resultados encontrados não foram configurados como categorias, entretanto, são dados importantes para caracterizarem mais detalhadamente o trabalho dos entrevistados.

Nesta pesquisa, foram definidas cinco categorias para análise: Limitações na atuação profissional; Técnicas de abordagem em ações educativas; Intuito das práticas educativas; Avaliação dos resultados; Possibilidades de ampliação das ações educativas em saúde (Quadro 1).

Primeiramente serão apresentados os dados não configurados como categorias que têm como objetivo caracterizar o cotidiano das práticas dos nutricionistas que participaram do estudo. Em seguida, serão apresentadas as categorias e os apontamentos relevantes.
Nas práticas educativas realizadas pelas nutricionistas, o público alvo "[...] é predominantemente de adultos vinculados a programas da SMS e os que têm maior adesão são os do programa para hipertensão e diabetes (HIPERDIA), que por a maioria ser idosa tem mais tempo para participar dessas atividades" E1.

Pode-se inferir que isso ocorre possivelmente pelo fato dos idosos terem maior tempo livre para comparecerem às atividades propostas. Nesse sentido, Viana et al. ${ }^{16}$ encontraram resultados semelhantes em seu estudo, afirmando que os usuários participantes de atividades física e educativa são, na sua maioria, idosa, do sexo feminino e com alguma enfermidade. Dificilmente envolvem adultos e jovens pela disponibilidade de tempo devido ao emprego. Outros estudos ${ }^{17-19}$ encontraram também maior frequência de pessoas aposentadas e do lar nas atividades educativas para hipertensos e diabéticos.

As nutricionistas relataram que há uma prevalência de hipertensos e diabéticos entre os usuários e que estes têm melhor adesão aos programas oferecidos pelas unidades de saúde: "Na nossa região, a maioria das unidades solicita atividade sobre alimentação e nutrição para o grupo de idosos, não especificamente para todos estes, mas para o grupo de hipertensos e diabéticos." E4. Os resultados obtidos por meio da observação corroboram os relatos nas entrevistas. Dos cinco grupos observados, três deles envolveram, em sua maioria, os idosos em suas atividades: $\mathrm{o}$ grupo de HIPERDIA, de terapia comunitária e de diabetes.

Quadro 1. Síntese da categorização das entrevistas.

\begin{tabular}{|l|l|l|}
\hline \multicolumn{1}{|c|}{ Categorias } & \multicolumn{1}{|c|}{ Subcategorias } & \multicolumn{1}{c|}{ Códigos } \\
\hline $\begin{array}{l}\text { Limitações na atuação } \\
\text { profissional }\end{array}$ & Gestão & $\begin{array}{l}\text { Falta de estrutura; Insuficiência de capacitação; } \\
\text { Produtividade }\end{array}$ \\
\cline { 2 - 3 } $\begin{array}{l}\text { Técnicas de abordagem em } \\
\text { ações educativas }\end{array}$ & Profissional & Falta de planejamento e de avaliação \\
\hline Intuito das práticas educativas & $\begin{array}{l}\text { Atividades práticas e demonstrativas; Estratégias que } \\
\text { facilitam a compreensão; Interatividade; Nível de } \\
\text { instrução do público alvo; Necessidade do grupo; }\end{array}$ \\
\hline Avaliação dos resultados & $\begin{array}{l}\text { Valorizar as falas e as experiências; Conscientização } \\
\text { e Mudança de hábitos; Conhecimentos prévios; } \\
\text { Valorização dos trabalhos em grupo; Qualidade de vida }\end{array}$ \\
\hline $\begin{array}{l}\text { Possibilidades de ampliação } \\
\text { das ações educativas em saúde }\end{array}$ & $\begin{array}{l}\text { Peso corporal, Glicemia e Hábitos alimentares; } \\
\text { Feedback }\end{array}$ \\
\hline
\end{tabular}

Fonte: Dados da pesquisadora. 
A adesão do paciente a uma determinada terapia depende de vários fatores, que envolvem a relação profissional-paciente, as condições de tratamento, o acesso ao serviço de saúde e ao medicamento prescrito, entre outros. Para isso, é importante uma linguagem clara à compreensão do paciente, além de uma relação interprofissional ética. A adesão é um fenômeno multidimensional, que envolve todos os atores inseridos no tratamento de doenças: o sistema de saúde, os profissionais, o paciente e a família ${ }^{20}$.

A adesão está relacionada com o planejamento do cuidado em saúde, a oferta de atividades educativas que promovam interação entre a equipe e a comunidade e entre os profissionais da equipe, ações que motivem a população a participarem, a buscarem aprender novos conceitos e a compartilhar experiências. Muitas vezes, as atividades desenvolvidas estão ligadas à entrega de medicamentos e renovação de receitas, sendo enfrentadas como presença obrigatória e não como um momento de reflexão e esclarecimentos de dúvidas. A linguagem profissional deve estar adequada aos objetivos e intenções do profissional, bem como a escuta ativa dos interesses e dificuldades da comunidade devem ser considerados para o planejamento de atividades educativas ${ }^{21}$.

Os materiais e as estratégias educativas mais utilizados pelos profissionais revelam as técnicas de trabalho e a forma como as atividades educativas são desenvolvidas. Os materiais utilizados preferencialmente pelos profissionais foram cartazes e folders: "Já usei folders e cartazes também. Quando são grupos menores, peço aos participantes para que leiam e a gente vai conversando a respeito." E6.

A partir das observações, notou-se que das cinco atividades, três abordavam o conteúdo proposto nos materiais do MS relativos à pirâmide alimentar, alimentação saudável para hipertensos, diabéticos e gestantes. Alguns profissionais ficam restritos apenas às recomendações desses materiais, outros trabalham questões que transcendem a alimentação.

Em relação às estratégias, foram elencadas palestra e roda de conversa como as mais utilizadas: "Como estratégia, utilizo palestra e também roda de conversa, oficina aqui não tem estrutura.” E8. As rodas de conversa são direcionadas a um tema específico, com discussões que envolvem o relato das pessoas e a interação entre elas, permitindo troca de experiências e de ideias ${ }^{22}$. A condução das rodas de conversas não foi possível ser observada.

A categoria Limitações na atuação profissional foi originada de duas subcategorias: gestão e pro- fissional. A subcategoria gestão agrega os fatores citados pelas entrevistadas (códigos): falta de estrutura (material, espaço físico e audiovisual). "A questão do material é uma grande limitação que temos para trabalhar em grupo, aqui a gente não tem recursos... na verdade existe um grande desestímulo às atividades de educação em saúde..." E3.

Neste discurso, percebe-se certa insatisfação da profissional em relação à atuação em educação em saúde, associada às limitações materiais e à falta de apoio da gestão municipal. A disponibilidade de materiais e de um ambiente físico adequados são vantagens para o bom desenvolvimento de ações educativas, tanto em nível individual quanto grupal. A insuficiência desses materiais e o espaço físico limitado dificultam o acesso aos serviços por parte do usuário ${ }^{23}$.

A insuficiência de capacitação também foi elencada como uma limitação para atuar no campo da educação em saúde bem como a valorização da produtividade em detrimento das atividades de cunho educativo de atendimentos em grupo, que prezam a qualidade e o melhor acesso à população.

A subcategoria profissional integra questões que podem ser interpretadas, possivelmente, como falha por parte dos nutricionistas em relação à atuação e também como sobrecarga de trabalho na função. Diante dos relatos, percebe-se que é comum a falta de planejamento das atividades e também de avaliação das implicações das ações realizadas.

Este relato ressalta que a falta de planejamento dificulta o desenvolvimento efetivo de ações educativas, sendo vista como uma limitação na atuação profissional: “[...] as atribuições são muitas [...] então não tem muito tempo para a gente fazer esse planejamento prévio, que seria o ideal, então a gente trabalha em cima do improviso mesmo $[\ldots]$ " E2.

O acúmulo de responsabilidades do cargo dificulta, na maioria das vezes, o acompanhamento dos usuários, por não haver vínculo da profissional com a unidade de saúde, tornando a sua demanda fragmentada. Essa atitude implica uma prática de educação em saúde desarticulada e enfraquecida.

Em relação à falta de avaliação das ações educativas, a maioria referiu não aplicar instrumentos de forma sistemática após as atividades. Elas declaram que confiam no conhecimento que a experiência lhes concede: "Pergunto se tem alguma dúvida, que geralmente eles têm no dia a dia, no mais é de acordo com que eles perguntam, uma avaliação minha mesmo eu não faço." E5. 
A categoria Técnicas de abordagem em ações educativas envolve as técnicas que atraem a participação dos usuários na construção do conhecimento compartilhado. Foram mencionadas algumas técnicas, como a prevalência de atividades práticas e demonstrativas. Outros elementos importantes que estão presentes na prática das entrevistadas são as estratégias que facilitam a compreensão e a interatividade na condução das atividades: “[...] quanto mais prático, mais palpável, visível para eles, parece que mais fica dessa atividade [...] utilizo muito alimentos mesmo, utensílios... para mostrar a eles formação de pratos e grupos de alimentos." E1.

As profissionais atentam também para o grau de instrução do público alvo, dessa forma enfatizam na linguagem e nos materiais utilizados uma comunicação simples para, assim, haver melhor compreensão das informações. Essas estratégias remetem ao modelo dialógico de educação, uma vez que as propostas citadas promovem a participação da comunidade, facilitam o envolvimento das pessoas na construção do saber compartilhado, porém, requerem habilidade do profissional em trabalhar como facilitador do processo ${ }^{24}$.

Outro aspecto levantado se refere à necessidade do grupo. As participantes apontaram que os temas trabalhados nas atividades são direcionados pela realidade do grupo, pelas condições de saúde mais comuns, pelas principais queixas e interesses da população.

A categoria intuito das práticas educativas destaca preocupações dos participantes acerca da qualidade dos serviços realizados. Elas procuram valorizar as falas e as experiências dos usuários no momento das atividades e objetivam a conscientização da comunidade para alcançar a meta da mudança de hábitos e, além disso, algumas entrevistadas apontaram também a valorização dos trabalhos em grupo. A realização de atividades em grupo permite a integração de pessoas diferentes, porém em uma mesma situação e com objetivos semelhantes. Essa integração facilita a troca de conhecimentos e de experiências, e o uso do diálogo como meio de comunicação nos grupos contribui para o surgimento de concepções novas sobre os temas discutidos ${ }^{25}$.

A alimentação e a nutrição são propostas discutidas desde a reforma sanitária e a criação do SUS, sendo esses campos temáticos de atuação do SUS previstos nas leis orgânicas da saúde. A área da alimentação se tornou protagonista no processo de atenção integral à saúde, se fortalecendo enquanto política (Política Nacional de Alimentação e Nutrição). Os relatos das nutricionistas em relação às estratégias educativas, realização das atividades em grupo, diversificação de temas e interatividade resumem os desafios da produção de saúde no cenário da organização da atenção nutricional, sobretudo na atenção básica ${ }^{26}$.

Ainda quanto às intenções dos profissionais, alguns demonstraram em seus relatos uma visão ampliada de saúde, na tentativa de promover um cuidado integral em relação às necessidades dos indivíduos. Os entrevistados buscam as condições de saúde em uma dimensão além da alimentação, contemplam outros aspectos que envolvem o ser humano, em busca da melhoria da qualidade de vida: "na maioria das vezes eu não trabalho só com educação nutricional... a saúde é uma questão holística e muito mais abrangente que só a questão da nutrição [...]." E3.

A promoção de saúde e qualidade de vida envolvem fatores correspondentes ao governo, à gestão integrada, às ações intersetoriais e às estratégias de vida saudável. As ações educativas dependem de um bom trabalho da equipe multiprofissional, do envolvimento da população de forma ativa e de apoio estrutural pela gestão, uma relação fortalecida pelo diálogo ${ }^{27}$.

A categoria avaliação dos resultados foi definida para reunir as formas de avaliação dos efeitos das atividades educativas elucidadas por algumas entrevistadas. Duas nutricionistas citaram aferir o peso corporal, a glicemia e verificar os hábitos alimentares por meio de questionamento verbal e afirmam utilizar esses dados como instrumento de avaliação.

Outra maneira de verificar se o público alvo agregou os conhecimentos trabalhados é pelo feedback. As profissionais ressaltaram que se baseiam no retorno que os pacientes dão ao final da atividade, estimulados pelo mediador a exporem sobre o conteúdo. Nos grupos observados, a avaliação ao final das atividades. Em todos eles as profissionais mediadoras estimularam os participantes a colocarem as dúvidas, os questionamentos e o que assimilaram da atividade.

A categoria Possibilidades de ampliação das ações educativas em saúde agrega a questão do trabalho em equipe, a parceria e o envolvimento com a equipe multiprofissional e também a tentativa de atender aos princípios do SUS: integralidade e equidade; desde o planejamento e o desenvolvimento até a avaliação das ações educativas. A maioria das entrevistadas enfatizou a importância do trabalho multiprofissional, reforçando a ideia do fortalecimento das ações: "A gente procura também relacionar uns temas com outros [...] a psicóloga está presente juntamente 
com a assistente social [...] procuramos através da interdisciplinaridade, transversalizar mesmo os temas." E7.

“[...] o ser humano é integral e tem outras preocupações também. Quando o profissional que vê o indivíduo como ser humano, que tem um fator familiar, social, econômico [...] a resolutividade e a efetividade das atividades são maiores." E3. Além dos aspectos nutricionais, os usuários trazem outras questões de saúde e condições sociais que os afeta. A partir do momento que o profissional tem essa percepção, nota-se que há um cuidado em colocar em prática os princípios do SUS, a saber: a integralidade e a equidade ${ }^{28}$.

A organização da atenção nutricional na perspectiva do cuidado integral busca atender o indivíduo em sua totalidade, se há a presença de uma enfermidade, não há como voltar o olhar apenas para a alimentação adequada àquela situação. A linha de cuidado proposta pelas Redes de Atenção à Saúde sugere a horizontalização da atenção, ou seja, considerar também os fatores relacionados, como os medicamentos utilizados, as condições de vida, a moradia, o trabalho, a renda, a família e os hábitos de vida e as condutas a serem tomadas desde a prevenção de doenças ou complicações até a recuperação e o tratamento ${ }^{26}$.

\section{O modelo conceitual}

A teoria fundamentada nos dados recomenda a elaboração do modelo conceitual que tem como finalidade a apresentação e a explicação do problema investigado que emergiu dos fatos e permite fazer correlações entre os achados e a literatura já existente.

Com base nas observações, confirmam-se alguns relatos das entrevistas, como, por exemplo, das nutricionistas que utilizaram alimentos para trabalhar a definição de porções e os rótulos de alimentos. Esta prática corrobora as estratégias educativas que se apoiam na demonstração ou simulação para aprendizagem ou reforço.

Os profissionais prezam o envolvimento dos usuários nas ações educativas, estimulam a participação de forma mais ativa para que haja o compartilhamento e a troca de saberes e experiências, atuando como facilitador da comunicação entre os participantes.

Ao refletir sobre os elementos das entrevistas e observações, percebe-se que muitos nutricionistas passaram a ver a educação em saúde pela lente do modelo dialógico. Tal percepção pode ser reafirmada pelo discurso nas entrevistas, ao defenderem as estratégias ativas em suas ativi- dades para superar a visão tecnicista de caráter meramente curativo.

A categoria intuito das práticas educativas retrata o que as profissionais realmente priorizam para trabalhar educação em saúde. $O$ fato de valorizarem as falas e as experiências dos usuários e considerarem seus conhecimentos prévios, expressa o compartilhamento de informações, sendo uma condição para a construção conjunta do saber. A profissional ouve o relato do usuário e, diante de sua realidade, conduz o processo educativo, como mediadora. A intenção da conscientização e mudança de hábitos da população salientam a preocupação da profissional em desenvolver ações articuladas e coerentes com o contexto no qual trabalha.

A valorização da produtividade foi levantada pelas entrevistadas como uma das limitações na atuação profissional. A atenção básica prioriza a promoção da saúde, entretanto, falta o apoio necessário para a execução das ações que fomentem esse objetivo. Ainda sobre a gestão, sobressaíram as queixas de insuficiência de capacitação profissional e falta de estrutura para realização de atividades educativas. Nota-se que essa situação expressa uma sequência de impactos negativos pela falta de apoio. Se os gestores privilegiam as consultas individuais, o foco dos investimentos será para tal em desfavor das atividades coletivas de educação em saúde. Quando os profissionais expandem o olhar para além da sua área de atuação, ele se permite ir adiante das queixas do usuário. Isso denota a visão integral que o modelo dialógico de saúde exige do profissional.

Constatou-se que a maior parte das entrevistadas não realiza avaliação dos seus resultados. Consequência, possivelmente, da falta de planejamento. Algumas entrevistadas aferem dados concretos, como o peso e a glicemia, a fim de avaliar resultados. Caso haja redução de peso no obeso ou redução dos níveis glicêmicos no diabético, isso pode representar a prática de hábitos mais saudáveis. Outros profissionais preferem confiar no feedback dos usuários, incentivando-os a expor as dúvidas ao final das atividades, como também o que aquele tema acrescentou aos conhecimentos individuais. Esse formato de avaliação assistemática possibilita ao profissional ter retorno daquilo que propôs ao grupo, porém, é um método subjetivo, pois depende de como ele analisará essas informações.

Por fim, as entrevistadas contribuíram ricamente sugerindo possibilidades de ampliação das ações educativas, que acreditam ser essenciais para a concretização do modelo dialógico na saú- 
de. Salientaram a importância da parceria com a equipe multiprofissional, permitindo uma troca que representa a busca de qualidade do atendimento.

Ao executar uma ação de saúde pautada no diálogo, na interação com a comunidade, empregando materiais práticos e estratégias ativas, com planejamento bem elaborado, contendo ferramentas de avaliação dos resultados, o profissional tem o objetivo de conscientizar o usuário para transformar sua realidade. Partindo desse princípio, ele deve identificar todas as necessidades daquele indivíduo para trabalhar cada uma em sua devida proporção ${ }^{28}$.

\section{Considerações finais}

A TFD possibilitou a construção do chamado modelo conceitual. A pesquisa pretendeu contribuir para a reflexão dos nutricionistas a respeito de sua atuação profissional, suscitar a busca de formação integral na educação e educação em saúde, investir em pesquisas nesse campo, a fim de que o processo de promoção de saúde seja trabalhado devidamente. Além disso, o intento também foi de ampliar nos atores envolvidos (usuários, gestores e trabalhadores) a construção de novos saberes. A pesquisa qualitativa oportuniza a reflexão, a crítica e a possível transformação da realidade, pois permite a análise dos sentidos dos discursos. Dessa forma, este estudo contribui para a valorização de pesquisa dessa natureza.

Em relação à concepção das nutricionistas a respeito da educação em saúde, percebe-se que a maioria defende a ideia da necessidade de com- partilhamento de saberes, de um processo libertador, da transformação da realidade do ser humano, corroborando com o modelo dialógico.

As estratégias mais utilizadas nas ações educativas envolvem elementos práticos e demonstrativos. Nem todos os relatos das participantes que tiveram sua atividade observada foram condizentes com a prática, tanto nas estratégias, quanto nos materiais utilizados. Pela limitação do estudo, que não permitiu a observação de uma sequência de atividades, não se pode afirmar que há uma contradição entre o discurso e a atuação.

As nutricionistas destacaram a insuficiência de cursos ou formações a respeito de práticas educativas oferecidos pela gestão da Secretaria Municipal de Saúde. A falta de providência da gestão em aprimorar o serviço, principalmente no que concerne às atividades educativas, leva o profissional a procurar, por iniciativa própria, uma formação continuada ou aprender com sua vivência no campo de trabalho compartilhado com outros profissionais, prática muitas vezes desarticulada da teoria.

A partir da reflexão empreendida, após a análise dos dados, acredita-se ser importante considerar o perfil do profissional. Se o nutricionista tem uma concepção tradicional, possivelmente utilizará as recomendações já publicadas e reproduzirá esse conhecimento, provavelmente não se preocupando com a metodologia empregada. Por outro lado, se o profissional compactuar com uma perspectiva dialógica de educação em saúde, explorará os conteúdos se atentando às técnicas e preocupar-se-á, também, com os efeitos resultantes dos processos empregados na educação em saúde do seu público alvo. 


\section{Colaboradores}

MSN Vieira participou na concepção, delineamento, análise e interpretação dos dados, redação e revisão do artigo. KK Matias participou da análise e interpretação dos dados, redação e revisão do artigo. MG Queiroz participou na concepção, delineamento, análise e interpretação dos dados, redação do artigo e como orientadora da pesquisa participou como revisora de todas as etapas na elaboração do artigo. Todos participaram da aprovação da versão a ser a ser publicada.

\section{Referências}

1. Freire P. Pedagogia do oprimido. 17 $7^{\mathrm{a}}$ ed. Rio de Janeiro: Paz e Terra; 1987.

2. Villa-Vélez L. Educación para la salud y justicia social basada en el enfoque de las capacidades: Una oportunidad para el desarrollo de la salud pública. Cien Saude Colet 2020; 25(4):1539-1546.

3. Malta DC, Reis AAC, Jaime PC, Morais Neto OL, Silva MMA, Akerman M. O SUS e a Política Nacional de Promoção da Saúde: perspectiva resultados, avanços e desafios em tempos de crise. Cienc Saude Colet 2018; 23(6):1799-1809.

4. Brasil. Ministério da Saúde (MS). Portaria no 2.436, de 21 de setembro de 2017. Aprova a Política Nacional de Atenção Básica, estabelecendo a revisão das diretrizes para organização da Atenção Básica no SUS. Diário Oficial da União 2017; 21 set.

5. Brasil. Ministério da Saúde (MS). Secretaria de Atenção à Saúde. Departamento de Atenção Básica. Núcleo de Apoio à Saúde da Família, v.1. Brasília: MS; 2014. (Cadernos de Atenção Básica, n. 39)

6. Marques HB. Concepções de trabalho, educação e saúde na formação e atuação profissional do nutricionista no âmbito da estratégia de saúde da família no município do Rio de Janeiro. [dissertação]. Rio de Janeiro: Fiocruz; 2018.

7. Macedo IC, Aquino RC. O Marco de Referência de Educação Alimentar e Nutricional para Políticas Públicas no Brasil no contexto do atendimento nutricional. Demetra 2018; 13(1):21-35.

8. Brasil. Ministério do Desenvolvimento Social e Combate à Fome (MDS). Marco de referência de educação alimentar e nutricional para as políticas públicas. Brasília: Secretaria Nacional de Segurança Alimentar e Nutricional; 2012.

9. Cervato-Mancuso AM.; Vincha KRR.; Santiago DA. Educação Alimentar e Nutricional como prática de intervenção: reflexão e possibilidades de fortalecimento. Physis 2016; 26(1):225-249.

10. Minayo MCS. O desafio do conhecimento: pesquisa qualitativa em saúde. 14ª ed. São Paulo: Hucitec; 2014.

11. Charmaz K. A construção da teoria fundamentada: guia prático para análise qualitativa. Porto Alegre: Artmed; 2009.

12. Leite F. Raciocínio e procedimentos da Grounded Theory Construtivista. Revista de Epistemologias da Comunicação 2015; 3(6):1-10.

13. Minayo MC, Deslandes S, Gomes R. Pesquisa Social: teoria, método e criatividade. Petrópolis: Vozes; 2016.

14. Cresweel JW. Investigação qualitativa e projeto de pesquisa: escolhendo entre cinco abordagens. $3^{\mathrm{a}} \mathrm{ed}$. Porto Alegre: Penso; 2014.

15. Brasil. Resolução no 466, de 12 de dezembro de 2012. Aprovar as diretrizes e normas regulamentadoras de pesquisas envolvendo seres humanos. Diário Oficial da União 2013; 13 jun.

16. Viana DA, Martins LC, Gonçalves AM. Educação em saúde como estratégia para promoção do envelhecimento saudável - revisão integrativa da literatura. JCBS 2016; 1(3):50-58.

17. Martins FTM, Camargo FC, Marques ALN, Guimarães HPN, Felipe LRR, Marques MM, Santos SA Vivências socioeducativas para promoção da saúde em idosos: avaliando a intervenção. REFACS [Internet]; 2019 [acessado 2020 Abr 13]; 7(2):175-185. 
18. Freitas JGA, Nielson SEO, Porto CC. Adesão ao tratamento farmacológico em idosos hipertensos: uma revisão integrativa da literatura. Rev Soc. Bra Clín Med 2015; 13(1):75-84.

19. Damaceno MJCF, Chirelli MQC. Implementação da Saúde do Idoso na Estratégia Saúde da Família: visão dos profissionais e gestores. Cien Saude Colet 2019; 24(5):1637-1646.

20. Pimentel D. Relações e conflitos éticos na prática de médicos e enfermeiros. Brasília: CFM; 2017.

21. Brasil. Ministério da Saúde (MS). Contribuições dos Núcleos de Apoio à Saúde da Família para a Atenção Nutricional. Brasília: MS; 2017.

22. Melo RHV, Felipe MCP, Cunha ATR, Vilar RLA, Pereira EJS, Carneiro NEA, Freitas NGHB, Diniz Júnior J. Roda de Conversa: uma Articulação Solidária entre Ensino, Serviço e Comunidade. Rev Bras Educ Med 2016; 40(2):301-309.

23. Melo EA, Miranda L, Silva AM, Limeira RMN. Dez anos dos Núcleos de Apoio à Saúde da Família (Nasf):problematizando alguns desafios. Saúde Debate 2018; 42(1):328-340.

24. Turci MA, Lima-Costa MF, Macinko J. Influência de fatores estruturais e organizacionais no desempenho da atenção primária à saúde em Belo Horizonte, Minas Gerais, Brasil, na avaliação de gestores e enfermeiros. Cad. Saúde Pública 2015; 31(9):1941-1952.

25. Reis MJ. Educação em Saúde na Atenção Primária à Saúde no Brasil: um olhar sobre os conteúdos divulgados nas revistas científicas de saúde coletiva de 1990 a 2015 [dissertação]. Rio de Janeiro: Escola Nacional de Saúde Pública Sergio Arouca; 2016.

26. Jaime PC, Delmue DCC, Campello T, Silva DO, Santos LMP. Um olhar sobre a agenda de alimentação e nutrição nos trinta anos do Sistema Único de Saúde. Cien Saude Colet 2018; 23(6):1829-1836.

27. Jorge MSB, Leitão IMTA, Sousa FSP, Brilhante APCR, Oliveira ACS. Gestão em saúde: modelos, desafios e possibilidades. In: Silva RM, Jorge MSB, Silva Junior AG, organizadores. Planejamento, gestão e avaliação nas práticas de saúde. Fortaleza: EdUECE; 2015. p. 249-269.

28. Vieira MSN, Matias KK, Queiroz MG. Práticas de Educação em Saúde por Nutricionistas. In: Anais do $7^{\circ}$. Congresso Ibero-Americano em Investigação Qualitativa; 2018; Fortaleza. p. 1302-1311.

Artigo apresentado em 26/03/2020

Aprovado em 03/05/2020

Versão final apresentada em 05/05/2020

Editores-chefes: Maria Cecília de Souza Minayo, Romeu Gomes, Antônio Augusto Moura da Silva 